Thorax (1974), 29, 595.

\title{
Primary diaphragmatic haemangiopericytoma
}

\author{
DOUGLAS SEATON \\ Regional Department of Medical Neurology, Walton Hospital, Liverpool
}

\begin{abstract}
Seaton, D. (1974). Thorax, 29, 595-598. Primary diaphragmatic haemangiopericytoma. Haemangiopericytomas are tumours consisting of vascular spaces surrounded by proliferating pericytes. Since this neoplasm was first described (Stout and Murray, 1942) over 300 cases have been reported. All tumours of the diaphragm are rare, and a primary diaphragmatic haemangiopericytoma has not been previously recorded in the English literature. Such a case is described and the features of haemangiopericytomas are discussed.
\end{abstract}

\section{CASE REPORT}

A 59-year-old woman was admitted to a medical ward with symptoms and signs suggestive of acute pyelonephritis. She gave no history of respiratory symptoms and, apart from the presence of a dorsal kyphosis, examination of the chest was normal. Finger clubbing was not present.

INVESTIGATIONS Mid-stream urine culture produced a heavy growth of Escherichia coli. Haemoglobin $12.9 \mathrm{~g} / 100 \mathrm{ml}$, white cell count $12,600 / \mathrm{mm}^{3}$, with a neutrophil leucocytosis; erythrocyte sedimentation rate $47 \mathrm{~mm} / \mathrm{hr}$. The following biochemical investigations were normal: plasma urea and electrolytes, blood sugar, plasma calcium and inorganic phosphate, serum bilirubin, plasma alkaline phosphatase, and plasma cholesterol. Intravenous pyelography was normal. Chest radiographs demonstrated a large, rounded, homogeneous opacity of soft-tissue density in the right lower zone situated posteriorly. This had a well-defined upper contour which was contiguous with the diaphragmatic shadow (Figs. 1 and 2). Tomography showed no calcification in the mass. A chest radiograph taken in 1967 had been normal. Hydatid complement fixation and Casoni tests were negative. Forced vital capacity was 2.4 litres; the forced expiratory volume in one second was $81 \%$ of the forced vital capacity; maximum breathing capacity was 74 litres per minute.

The radiographic findings were thought to indicate a bronchogenic or metastatic carcinoma. A neurogenic tumour was considered although there was no extension to or widening of the intervertebral foramina and no splaying of adjacent ribs. The rounded appearance of the shadow was suggestive of an echinococcal cyst, but serological testing was negative and no calcification was seen radiographically. The unusual possibility of a diaphragmatic tumour or cyst was also considered.

The patient's urinary infection responded to treatment with an antibiotic. Bronchoscopy was normal.

OPERATION At thoracotomy (Mr. L. J. Temple) a firm well-circumscribed, grey-coloured tumour was found. It was adherent to the chest wall but was separable extrapleurally. The right hemidiaphragm was involved by the tumour, part of which extended below it. The liver was not involved. There were some protruberances of tumour adherent to the lung and a small part of the latter was therefore excised with the mass. The postoperative course was uneventful and a year later the patient remained well.

PATHOLOGICAL FINDINGS The rounded tumour measured $6 \times 5 \times 6 \mathrm{~cm}$ and was thickly encapsulated. Diaphragmatic tissue formed a rim below its centre (Fig. 3), beneath which the tumour was coarsely lobulated. The cut surface was firm and light grey in colour and contained some areas of haemorrhage but no necrosis. The microscopic appearance was of solid acini of regular rounded tumour cells, mainly showing a peritheliomatous pattern. The neoplasm was divided into irregular lobules by a fine fibrous stroma containing blood vessels which were in continuity with the thin-walled vascular spaces in the tumour acini (Fig. 4). The tumour cells had regular hyperchromatic nuclei which showed few mitoses, and the clear cytoplasm was eosinophilic but scanty. Silver impregnation showed a fine reticulin pattern surrounding both vascular channels and adjacent small groups of tumour cells (Fig. 5). The features were characteristic of a haemangiopericytoma. 


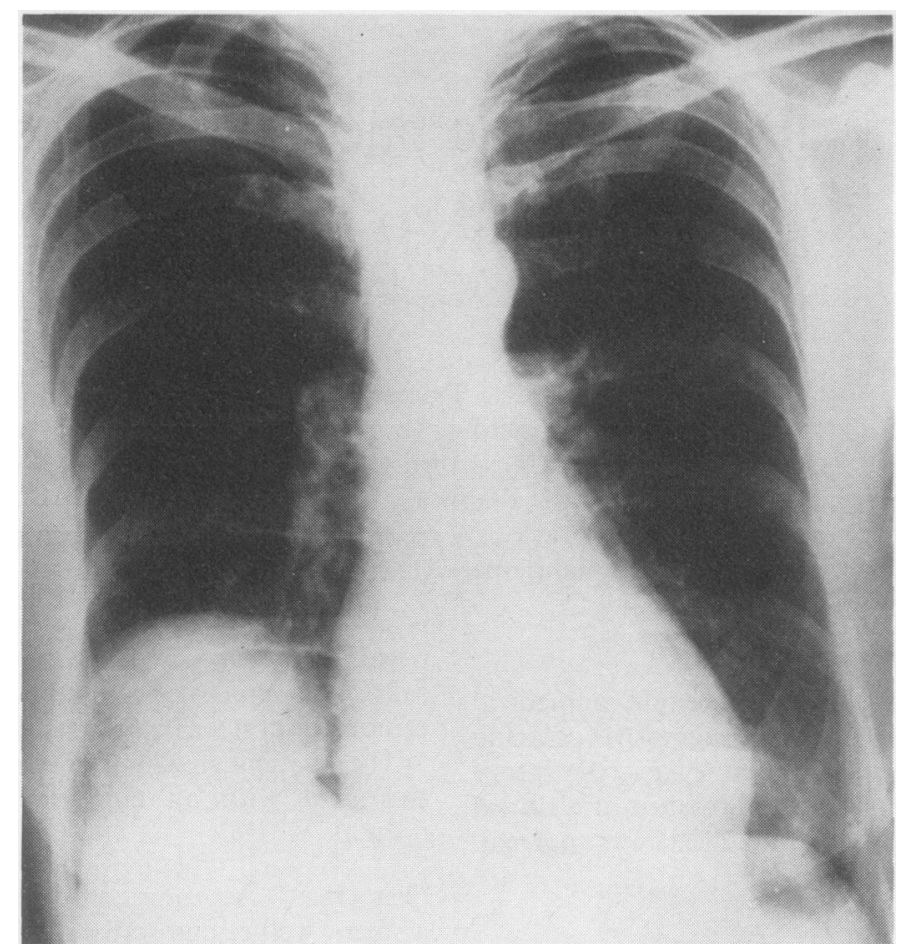

FIG. 1. Chest radiograph, postero-anterior view, showing the tumour in the right lower zone.

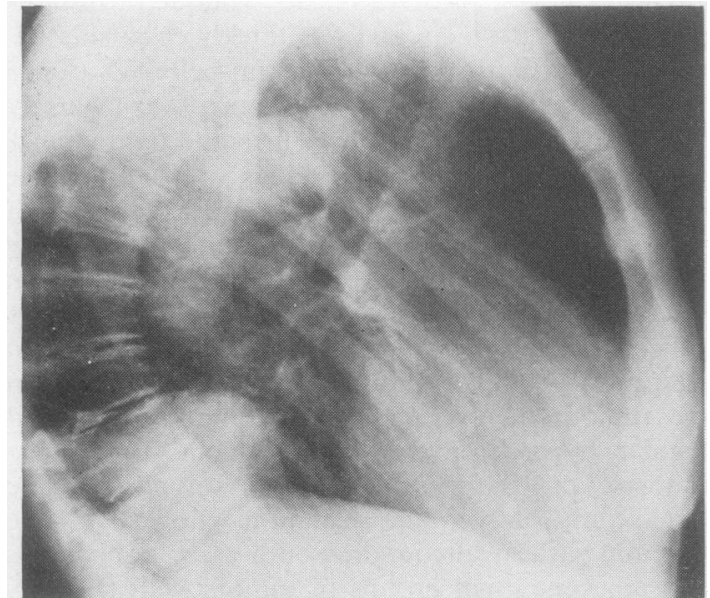

FIG. 2. Chest radiograph, right lateral view, showing the tumour situated posteriorly.

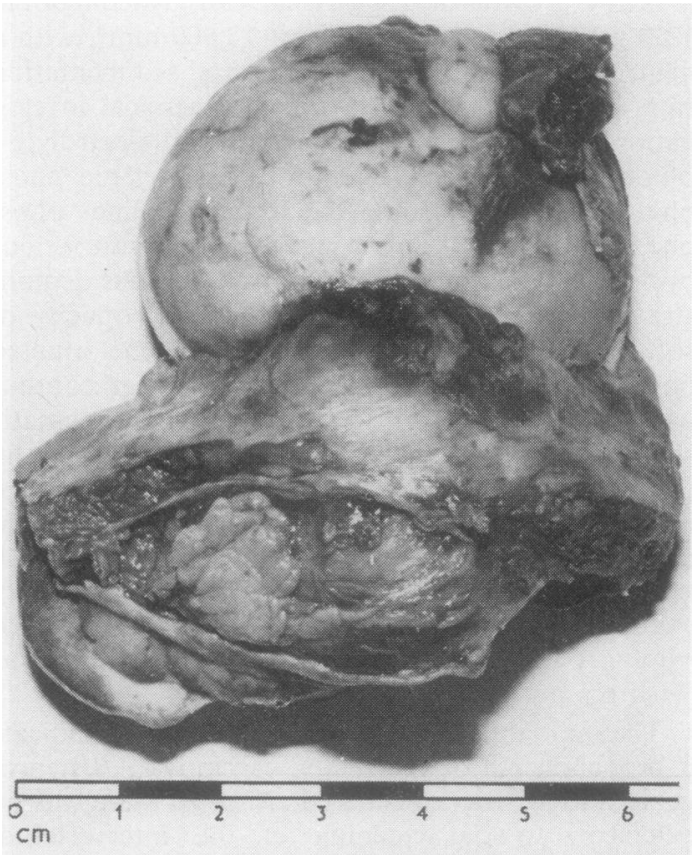

FIG. 3. Haemangiopericytoma extending above and below $\mathbb{\mathbb { D }}$ the diaphragmatic fragment. A small piece of lung is adherent to the upper pole of the tumour. 


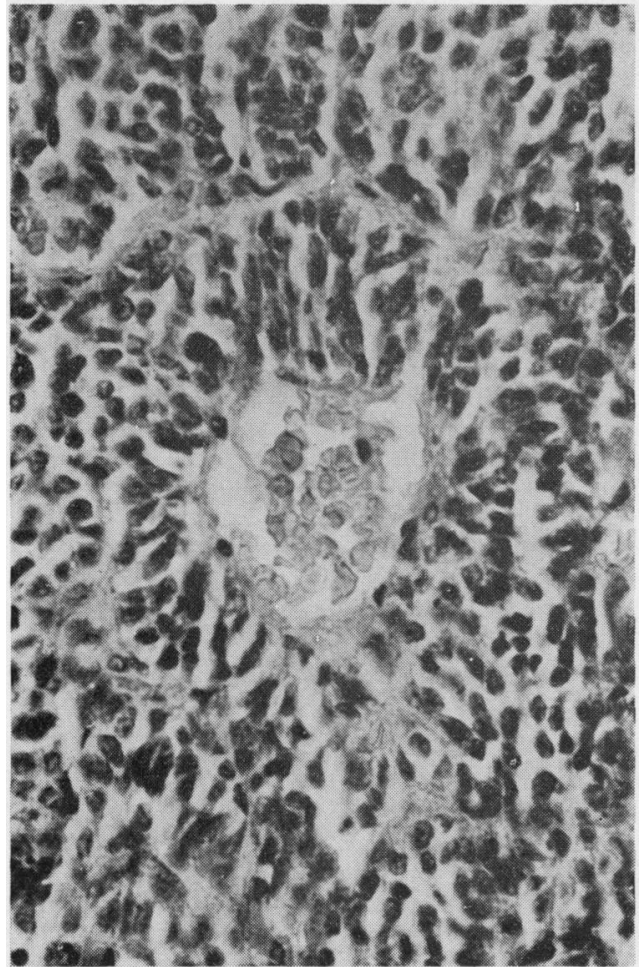

FIG. 4. Haemangiopericytoma. An acinar arrangement of tumour cells surrounds a thin-walled vascular space. Haematoxylin and eosin stain, $\times 480$.

\section{DISCUSSION}

Pericytes normally form an integral part of capillary walls. Although they are in continuity with the smooth muscle layers of adjacent arterioles and venules (Zimmermann, 1923), electron microscopy has shown them to differ markedly from vascular smooth muscle cells (Movat and Fernando, 1964). Pericytes have phagocytic properties (Majno and Palade, 1961) and it has been suggested that they are multipotent and are capable of antibody production (Movat and Fernando, 1964). Haemangiopericytomas are mesenchymal tumours consisting of numerous endothelium-lined spaces surrounded by a proliferation of rounded or slightly elongated cells derived from pericytes (Stout and Murray, 1942). Haemangiopericytomas must be differentiated histologically from glomus tumours (which are usually superficial and painful), from haemangioendotheliomas, capillary haemangiomas, and chemodectomas. Glomus tumours have an organoid structure based on the neuromyoarterial glomus and contain numerous nerve axis cylinders. In haemangioendotheliomas, neoplastic cells derived from endo-

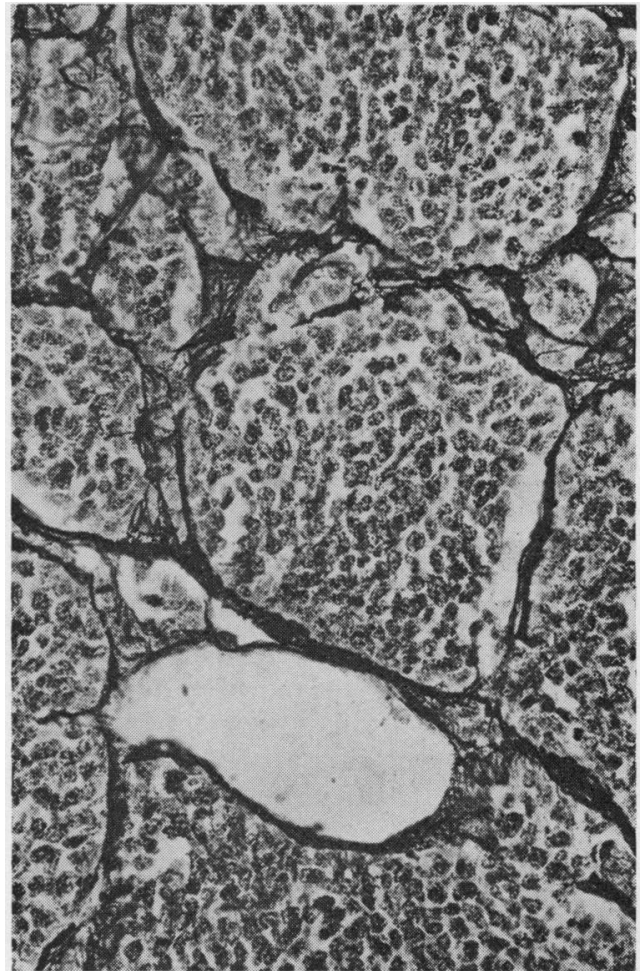

FIG. 5. Haemangiopericytoma. Groups of tumour cells and a vascular space surrounded by a network of reticulin fibres. Silver reticulin stain, $\times 360$.

thelium heap up intraluminally, invade the vessel wall, and proliferate outside it. The use of a silver connective tissue stain is therefore valuable for demonstrating that the tumour cells in haemangiopericytomas lie outside the capillary reticulin sheaths, the vascular endothelium remaining intact (Stout, 1949). In simple capillary haemangiomas, the perivascular tumour cells typical of haemangiopericytomas are absent. In chemodectomas there is a more definite alveolar arrangement of tumour cells, each group being surrounded by reticulin.

Haemangiopericytomas are frequently described as tan-coloured and they vary greatly in size, tumours weighing more than $1 \mathrm{~kg}$ having been recorded. Their vascular origin causes them to be ubiquitous, but the most common site is the musculoskeletal system. They occur with approximately equal frequency in both sexes, from birth to old age, the peak distribution falling in the fifth or sixth decades.

Intrathoracic haemangiopericytomas are often symptomless. In a review of 25 cases of primary pulmonary haemangiopericytoma, 12 patients were free of symptoms when the tumour was detected 
(Meade, Whitwell, Bickford, and Waddington, 1974). They may, however, present with cough, dyspnoea or pain and may cause erosion of bone or hypertrophic pulmonary osteoarthropathy (Feldman and Seaman, 1964). Other non-metastatic effects of haemangiopericytomas include hypoglycaemia (Crocker and Veith, 1965), masculinization (Howard and Davis, 1959), and hypertension in renin-secreting tumours of the kidney (Eddy and Sanchez, 1971).

Haemangiopericytomas are potentially malignant, and it is very difficult histologically to predict which tumours will recur. Growth may be rapid or extremely slow; indeed, the presence of a tumour for 60 years is recorded in one patient (Stout and Cassel, 1943). The treatment of choice is wide surgical excision as the tumours are relatively resistant to radiotherapy (Backwinkel and Diddams, 1970). Extended observation of patients postoperatively is desirable for although the mortality during the first five years of follow-up in a series of 23 cases was $21.7 \%$, the total mortality at the end of a 21 -year period was $47 \cdot 8 \%$ (O'Brien and Brasfield, 1965).

I am grateful to Dr. B. K. Ellenbogen and Mr. L. J. Temple for permission to report this case, and to Dr. F. Whitwell for details of the tumour pathology.

\section{REFERENCES}

Backwinkel, K. D. and Diddams, J. A. (1970). Hemangiopericytoma: report of a case and comprehensive review of the literature. Cancer, 25, 896.

Crocker, D. W. and Veith, F. J. (1965). Mesodermal tumors associated with hypoglycemia; review of the literature and report of a case. Annals of Surgery, $161,418$.
Eddy, R. L. and Sanchez, S. A. (1971). Renin-secreting renal neoplasm and hypertension with hypokalemia. Annals of Internal Medicine, 75, 725.

Feldman, F. and Seaman, W. B. (1964). Primary thoracic hemangiopericytoma. Radiology, 82, 998.

Howard, J. W. and Davis, P. L. (1959). Retroperitoneal hemangiopericytoma associated with hypoglycemia and masculinization. Delaware State Medical Journal, 31, 29.

Majno, G. and Palade, G. E. (1961). Studies on inflammation. I. The effect of histamine and serotonin on vascular permeability: an electron microscopic study. Journal of Biophysical and Biochemical ir Cytology, 11, 571.

Meade, J. B., Whitwell, F., Bickford, B. J., and Wadding- of ton, J. K. B. (1974). Primary haemangiopericytoma 윽 of lung. Thorax, 29, 1.

Movat, H. Z. and Fernando, N. V. P. (1964). The fine $C$ structure of the terminal vascular bed. IV. The $\mathbb{D}$ venules and their perivascular cells. Experimental and $\overrightarrow{\mathbb{D}}$ Molecular Pathology, 3, 98.

O'Brien, P. and Brasfield, R. D. (1965). Hemangiopericytoma. Cancer, 18, 249.

Stout, A. P. (1949). Hemangiopericytoma: a study of twenty-five new cases. Cancer, 2, 1027. and Cassel, C. (1943). Hemangiopericytoma of the omentum. Surgery, 13, 578.

and Murray, M. R. (1942). Hemangiopericytoma: a vascular tumor featuring Zimmermann's pericytes Annals of Surgery, 116, 26.

Zimmermann, K. W. (1923). Der feinere Bau der Blutcapillären. Zeitschrift für Anatomie und Entwick- Oे lungsgeschichte, 68, 29.

Requests for reprints to: Dr. D. Seaton, Regional Department of Medical Neurology, Walton Hospital, Liverpool L9 $1 \mathrm{AE}$. 